\title{
High prevalence of asthma in five remote indigenous communities in Australia
}

\author{
P.C. Valery*, A.B. Chang", S. Shibasaki ${ }^{\ddagger}$, O. Gibson ${ }^{+}$, D.M. Purdie*, C. Shannon*, I.B. Masters ${ }^{\S}$
}

High prevalence of asthma in five remote indigenous communities in Australia. P.C. Valery, A.B. Chang, S. Shibasaki, O. Gibson, D. M. Purdie, C. Shannon, I.B. Masters. (C) ERS Journals Ltd 2001.

ABSTRACT: Data on the prevalence of asthma in children residing in remote indigenous communities in Australia are sparse, despite the many reports of high prevalence in nonindigenous children of this country. Two previous Australian studies have had poor participation rates, limiting interpretation of their results.

A study of children in the Torres Strait and Northern Peninsula Area of Australia was conducted to document the prevalence of asthma symptoms. Five indigenous communities were randomly selected and trained interviewers, who were local indigenous health workers, recruited participants using a house-by-house approach. Information was collected by a structured face-to-face interview based on a standardized questionnaire constructed from the protocol International Study of Asthma and Allergy in Childhood; 1,650 children were included in the study with a $98 \%$ response rate.

Overall, the prevalence of self-reported ever wheezing was $21 \% ; 12 \%$ reported wheezing in the previous year; and $16 \%$ reported ever having asthma. There was significant variation in the prevalence of asthma symptoms between communities.

It is concluded that there are significant intercommunity variations in the prevalence of asthma symptoms in remote communities and that the prevalence in these communities is as high as in nonindigenous groups.

Eur Respir J 2001; 17: 1089-1096.
*Epidemiology and Population Health Division, Queensland Institute of Medical Research, Queensland, Australia, ${ }^{\#}$ Dept of Paediatrics, Flinders University Northern Territory Clinical School, Dept of Paediatrics, Alice Springs Hospital, Australia, National Centre of Epidemiology and Population Health, Australian National University, Canberra, Australia, ${ }^{+}$Indigenous Health Program, University of Queensland, Queensland, Australia and ${ }^{\S}$ Dept of Respiratory Medicine, Royal Children's Hospital, Brisbane, Australia.

Correspondence: P.C. Valery, Epidemiology and Population Health Division, Queensland Institute of Medical Research, Post Office, Royal Brisbane Hospital, Queensland, Australia 4029. Fax: 61733620101

Keywords: Asthma

childhood

indigenous

Received: November 242000

Accepted after revision March 102001
Australian children have some of the highest known prevalence rates of asthma, ranging $17-19.5 \%$ [1]. Amongst Aboriginal and Torres Strait Islander children, who comprise $\sim 2 \%$ [2] of the Australian indigenous children, data on asthma prevalence are sparse and controversial. Indeed, the prevalence of asthma in indigenous communities in Australia was thought to be extremely low $(0-3.3 \%)$ [3, 4]. Specifically in the Torres Strait region, using an interviewer-administered questionnaire, VEALE et al. [3] found that the overall prevalence of wheeze in the last 12 months in those aged $5-19$ yrs was $4.6 \%$. However, more recent reports from different regions of Australia showed higher prevalences (up to $24 \%$ ) [5]. Indeed, the team from the Indigenous Health Paediatric Respiratory Outreach Program, as part of their clinical service in the Torres Strait region, diagnosed asthma in many children referred by local health workers [6]. Notwithstanding that there was a wide range of methods used in previous studies (different questionnaires, wide range of age groups, and the use of different tests), the reason for this apparent variation in asthma rates between communities and over time, as well as the effect of asthma in terms of morbidity and mortality, is open to conjecture.

In view of this, it was hypothesized that the prevalence of asthma symptoms in the Torres Strait and the Northern Peninsula Area may be higher than previously reported. Therefore, a study of childhood asthma in the Torres Strait and the Northern Peninsula Area was carried out to document the prevalence of asthma symptoms in children and adolescents living in five communities in the Torres Strait and the Northern Peninsula Area, Australia.

\section{Methods}

Study design and subjects

The Torres Strait, situated between Papua New Guinea and Cape York Peninsula, Australia, is an archipelago of $\sim 150$ islands with 15 indigenous communities. The Northern Peninsula Area has five indigenous communities that are situated at the tip of Cape York Peninsula, mainland Australia. This crosssectional study randomly selected five from these 20 


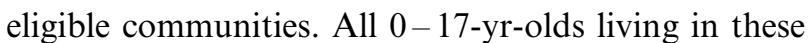
communities were eligible to take part. There were three island communities: Thursday Island, (the central business district), Warraber Island which is $\sim 70 \mathrm{~km}$ away from Thursday Island in the mid Torres Strait, and Saibai Island which is $120 \mathrm{~km}$ away (3 km from Papua New Guinea). The mainland communities were Bamaga and Umagico, which are $3 \mathrm{~km}$ apart. Geographically, the Torres Strait Islands are unique in that they are isolated from the Australian mainland and from the other island communities themselves by vast amounts of water. The uniqueness of the Northern Peninsula Area lies not only in its geographical isolation from the mainland but in Thursday Island being the area's central business district. According to the 1996 Census of Population and Housing [2], the indigenous population of the Torres Strait region was $\sim 7,000$ people, of which nearly 4,000 were from the five sampled communities. Across Australia, $40 \%$ of indigenous people had left school before age $16 \mathrm{yrs}$, compared to $34 \%$ of nonindigenous people [2]. At the time of the census the unemployment rate was $23 \%$ for indigenous people while that for nonindigenous people was 9\%. Torres Strait Islanders have comparable levels regarding the labour force status but appear to achieve higher levels of formal education and to be better qualified than indigenous people nationally [7].

\section{Questionnaire}

Information was collected by a structured face-toface interview with the caregiver or the children (when $>14$ yrs) based on a standardized validated questionnaire used in the International Study of Asthma and Allergy in Childhood (ISAAC) [8]. All eight questions from its core questionnaire for wheezing and asthma were included (see Appendix). In addition to these items, information was collected on the age and sex of the child, education status of the caregiver, parents ethnicity, employment status of all adults living in the household (total number of employed and unemployed adults in each house), and a few additional questions on asthma symptoms and medication. Because the household often contained many extended family members, the household employment status was categorized into three groups; mostly unemployed; even numbers of employed and unemployed adults or an excess of one employed; and mostly employed (excess of two or more employed adults). Information obtained on the education attainment was categorized into: not completed high school (no further training); not completed high school (further training); and completed high school or further tertiary training. Using the information on the parents ethnic background, the child's ethnicity was categorized into: indigenous (both parents indigenous); one parent indigenous; Caucasian parents; South Pacific Islanders; and others. No other data on the relevant risk factors for asthma were collected.

English is often not Torres Strait Islander people's first language, therefore translation for key questionnaire words into the local idiom (Creole) were adopted. Community elders, in consultation with survey staff, carried out the process of language modification. The questions were kept as in the original ISAAC questionnaire; a few key Creole words were added, with the English version of adopted local words kept in brackets to be used with those carers who only spoke English (see Appendix). If subjects did not understand terms such as "whistling sound in the chest" (wheezing) or "short wind" (asthma), as discussed in workshops conducted prior to data collection, the interviewers explained the terms to them in their local language.

\section{Data collection}

Study communities were contacted through their Councils for consultation. Information about the study was made available through posters, radio interviews, local newspapers, school newsletters, and personally by the interviewers themselves. The emphases were on the burden of asthma in the community and the importance of having all children included in the study, including those who never had asthma. All interviewers were of Aboriginal and Torres Strait Island descent and were mostly local health workers. Workshops were conducted locally to explain to the interviewers the study purpose, hypothesis, questionnaire and the need for accurate and consistent reporting. There were 13 interviewers, with $70 \%$ of the interviews performed by three of them. Interviewer consistency was assessed as a percentage of agreement between two interviewers (two of the three interviewers who performed most interviews were tested). Data collection was undertaken during a 3-month period (August-October 1999). Interviews were carried out at a place convenient for subjects, mostly in the home.

The trained interviewers and survey team, in an attempt to include all children in every household, recruited participants house-by-house (including all buildings such as business premises, churches and hospitals). Buildings were listed and three attempts on three different days were made at each eligible household (homes with at least one child $<18$ yrs living there) before assigning "no answer" for that household. For each eligible child, three attempts on three different days were made to complete the interview before assigning the individual child as "no answer". Preferred respondents were the carers (mostly mothers) of children aged $0-13$ yrs and the teenagers themselves for those aged 14-17 yrs.

\section{Statistical analysis}

Data were entered using Epi-Info software (version 6.0; Centres for Disease Control and Prevention, Atlanta, GA, USA) and all calculations performed using the Statistical Package for the Social Sciences (SPSS) software package (version 9.0; SPSS Inc., Chicago, IL, USA). Basic descriptive summaries were compiled for each community and described in 
different age groups, for males and females (presented as percentages). Prevalence of asthma symptoms, along with 95\% confidence intervals [9], were calculated for the different communities. Comparisons between the groups were performed using a Chisquared test, and logistic regression analysis was used to make comparisons while taking into account possible confounding factors.

\section{Results}

Of a total of 1,120 buildings listed, 565 were included in the study and 510 either did not have any eligible children in the house or were business or government premises. The remaining $45(4 \%)$ were refusals or empty households at the time of the interviewer's visit. There were 1,682 eligible children aged $0-17$ yrs identified, with 1,650 children participating in the study $(98.1 \%)$. The participation rates in Thursday Island, Saibai Island, Warraber Island, Bamaga and Umagico were 97.3\%, 99.3\%, 100.0\%, $99.4 \%$ and $97.9 \%$, respectively. Interviewer consistency (between two interviewers) ranged from $92-100 \%$.

Selected demographic characteristics of the study population are shown in table 1 . The male to female ratio was $1: 1$. The majority of children were aged $<10$ yrs $(62.7 \%)$. However, there was considerable intercommunity variation. Thursday Island had the highest proportion of children aged $>10 \mathrm{yrs}$, while Umagico had the highest proportion of children aged $<10$ yrs ( $p$-value $=0.007$ ). Most of the children included in the study $(89.4 \%)$ were indigenous. Thursday Island had the highest proportion of
Caucasian children (8.6\%), Saibai Island had the highest proportion of South Sea Islanders (13.2\%) and Umagico and Warraber had the highest proportion of Indigenous children, $100 \%$ and $98.1 \%$, respectively (p-value $<0.001$ ).

There were considerable variations in the education and employment status across the communities as well ( $\mathrm{p}$-value $<0.001$ and $\mathrm{p}$-value $<0.001$, respectively). Thursday Island had the highest proportion of carers in the higher education category (66.8\%) and Umagico had the lowest $(14.3 \%)$. Of the total group, more than half of caregivers $(53.8 \%)$ had completed high school or had done further tertiary studies, $15.5 \%$ had not completed high school but had additional training, such as apprenticeship or had a certificate, and $30.7 \%$ had not completed high school or further training. Thursday Island had the lowest level of unemployment, whilst Umagico had the highest. When nonindigenous children were excluded from the analysis, the demographic characteristics were very similar to the aforementioned.

The overall self-reported prevalence of ever wheezing was $20.6 \%, 12.4 \%$ reported wheezing in the previous 12 months, 8.9\% reported that they tired more easily than other children, $8.5 \%$ became more short of breath than other children, $7.8 \%$ reported wheezing after exercise and $15.8 \%$ reported ever having asthma (table 2). When the prevalence of symptoms were compared across different communities, there was considerable intercommunity variation (table 2 ) with most of these being statistically significant (crude p-values ranged $0.001-0.074)$. When sociodemographic differences between communities were taken

Table 1.-Selected demographic characteristics of study population

\begin{tabular}{|c|c|c|c|c|c|c|c|}
\hline & $\begin{array}{c}\text { Thursday } \\
\text { Island }\end{array}$ & $\begin{array}{l}\text { Saibai } \\
\text { Island }\end{array}$ & $\begin{array}{l}\text { Warraber } \\
\text { Island }\end{array}$ & Bamaga & Umagico & p-value & Total \\
\hline Subjects $n$ & 978 & 143 & 102 & 335 & 92 & & 1650 \\
\hline \multicolumn{8}{|l|}{ Ethnic background* } \\
\hline Indigenous (both parents) & 75.5 & 69.1 & 94.1 & 82.6 & 100 & \multirow{5}{*}{0.0001} & $1246(79.0)$ \\
\hline One parent indigenous & 12.4 & 13.2 & 4.0 & 8.6 & & & $164(10.4)$ \\
\hline Caucasian parents & 8.6 & 1.5 & & 5.8 & & & $100(6.3)$ \\
\hline South Pacific Islander parents & 2.8 & 13.2 & & 1.5 & & & $49(3.1)$ \\
\hline Others & 0.8 & 2.9 & 2.0 & 1.5 & & & $18(1.1)$ \\
\hline \multicolumn{8}{|l|}{ Age yrs } \\
\hline $0-4$ & 30.0 & 34.3 & 27.7 & 38.1 & 37.0 & \multirow{4}{*}{0.007} & $530(32.3)$ \\
\hline $5-9$ & 28.3 & 32.9 & 37.6 & 31.5 & 35.9 & & $499(30.4)$ \\
\hline $10-14$ & 26.4 & 23.8 & 25.7 & 21.0 & 18.5 & & $404(25.6)$ \\
\hline$\geqslant 15$ & 15.3 & 9.1 & 8.9 & 9.3 & 8.7 & & $210(12.8)$ \\
\hline \multicolumn{8}{|l|}{ Sex** } \\
\hline Male & 53.3 & 58.5 & 51.0 & 54.0 & 46.7 & \multirow{2}{*}{0.494} & $878(53.4)$ \\
\hline Female & 46.7 & 41.5 & 49.0 & 46.0 & 53.3 & & $767(46.6)$ \\
\hline \multicolumn{8}{|l|}{ Carer's level of education*** } \\
\hline Not completed high school (no further training) & 21.9 & 48.2 & 52.8 & 30.6 & 50.5 & \multirow{3}{*}{0.0001} & 413(30.7) \\
\hline Not completed high school (further training) & 11.3 & 4.3 & 6.7 & 26.6 & 35.2 & & $209(15.5)$ \\
\hline Completed high school or further tertiary training & 66.8 & 47.5 & 40.4 & 42.8 & 14.3 & & $725(53.8)$ \\
\hline \multicolumn{8}{|l|}{ Household employment status } \\
\hline Mostly unemployed & 12.0 & 53.1 & 67.6 & 33.7 & 92.4 & \multirow[t]{3}{*}{0.0001} & 460(27.9) \\
\hline Even numbers/excess one adult employed & 47.4 & 25.9 & 32.4 & 30.4 & 7.6 & & $642(38.9)$ \\
\hline Mostly employed & 40.6 & 21.0 & & 35.8 & & & $547(33.2)$ \\
\hline
\end{tabular}

Data presented as $\%$ or $\mathrm{n}(\%)$ unless otherwise stated. *: Information missing for 73 subjects (evenly distributed across communities); **: information missing for five subjects; ***: information missing for 303 subjects (Thursday Island had the highest proportion of missing data $(28 \%)$ following by Warraber Island $(13 \%))$. 
into account, self-report of ever wheezing, ever having asthma or taking asthma medication in the last 12 months remained significant (adjusted p-values were $0.048,0.012$ and 0.028 , respectively). The main confounding factors effecting variation in asthma symptoms across the communities were age and sex. For wheezing in the last 12 months, employment status and carer's education were also influential confounding factors and for the question "More short of breath than other children?" carer's education was also a confounding factor. Bamaga had the highest proportions of asthma symptoms (ever wheezing, ever had asthma and taken asthma medication), while Saibai Island and Umagico had the lowest (Umagico scored lowest for ever wheezing, and taken asthma medication, while Saibai Island scored lowest for ever having asthma).

For those children who reported wheezing in the last 12 months, 120 reported wheezing that was severe enough to disturb their sleep $(65.3 \%)$ and $43(23.4 \%)$ reported that it affected their speech. When these symptoms were stratified across demographic factors (table 3), only the number of asthma attacks in the last 12 months was significantly different across different levels of education of the carer, with those reporting $1-3$ asthma attacks having the highest proportion of carers with the lowest education attainment.

When the main three asthma symptoms were stratified by demographic factors (table 4), there were small differences between the ethnic groups although these were not statistically significant. For most questions, prevalence of symptoms did not vary greatly across age groups, except for wheezing in the last 12 months where there were higher proportions of children in the lower age groups reporting this symptom $(p$-value $=0.003)$. Self-reports of "ever had wheezing?" and "wheezing in the last 12 months?" varied across sex, levels of carer's education and employment status. In general, males were more likely to report symptoms than females. Those living in households with most people employed and whose carers were more educated were more likely to have ever wheezed and have wheezed in the last 12 months (p-values ranged $0.003-0.013$ ).

\section{Discussion}

This cross-sectional survey, which utilized an indigenous health model where local health workers have an important role in healthcare, has shown that the prevalence of asthma symptoms in Aboriginal and Torres Strait Islander children living in the Torres Strait region is as high as $20.6 \%$. This is much higher than previously reported [3], higher than black American children $(13.4 \%)$, similar to Hispanic American children (20.1\%) [10] and to nonindigenous Australians who have one of the highest prevalence rates in the world $[11,12]$.

The differences between this study and that which VEALE et al. [3] have undertaken in this locality could be attributed to several factors: those related to epidemiological study methods (different questionnaires, 
Table 3. - For the 205 children reporting wheezing in the last 12 months, prevalence and $95 \%$ confidence intervals of selected questions related to severity of asthma attacks by age, carer's education and employment status

\begin{tabular}{|c|c|c|c|c|c|}
\hline & \multicolumn{3}{|c|}{$\begin{array}{l}\text { Number of attacks of wheezing } \\
\text { in the last } 12 \text { months?* }\end{array}$} & \multirow{2}{*}{$\begin{array}{l}\text { Sleep disturbance } \\
\text { due to wheezing in } \\
\text { the last } 12 \text { months? } \\
\text { Ever }\end{array}$} & \multirow{2}{*}{$\begin{array}{l}\text { In the last } 12 \text { months } \\
\text { has wheezing limited } \\
\text { child's speech? } \\
\text { Yes }\end{array}$} \\
\hline & $1-3$ & $4-12$ & $\geqslant 12$ & & \\
\hline \multicolumn{6}{|l|}{ Age yrs } \\
\hline $0-4$ & $\begin{array}{c}46.8 \\
(38.5-55.1)\end{array}$ & $\begin{array}{c}56.3 \\
(39.1-73.4)\end{array}$ & $\begin{array}{c}70.0 \\
(41.6-98.4)\end{array}$ & $\begin{array}{c}50.8 \\
(41.9-59.8)\end{array}$ & $\begin{array}{c}44.2 \\
(29.3-59.0)\end{array}$ \\
\hline $5-9$ & $\begin{array}{c}26.6 \\
(19.3-34.0)\end{array}$ & $\begin{array}{c}18.8 \\
(5.2-32.3)\end{array}$ & $\begin{array}{c}10.0 \\
(0-28.6)\end{array}$ & $\begin{array}{c}25.0 \\
(17.3-32.7)\end{array}$ & $\begin{array}{c}18.6 \\
(7.0-30.2)\end{array}$ \\
\hline $10-14$ & $\begin{array}{c}17.3 \\
(11.0-23.5)\end{array}$ & $\begin{array}{c}18.8 \\
(5.2-32.3)\end{array}$ & $\begin{array}{c}10.0 \\
(0-28.6)\end{array}$ & $\begin{array}{c}15.8 \\
(9.3-22.4)\end{array}$ & $\begin{array}{c}23.3 \\
(10.6-35.9)\end{array}$ \\
\hline $15-17$ & $\begin{array}{c}9.4 \\
(4.5-14.2)\end{array}$ & $\begin{array}{c}6.3 \\
(0-14.6)\end{array}$ & $\begin{array}{c}10.0 \\
(0-28.6)\end{array}$ & $\begin{array}{c}8.3 \\
(3.4-13.3)\end{array}$ & $\begin{array}{c}14.0 \\
(3.6-24.3)\end{array}$ \\
\hline p-Value ${ }^{+}$ & & 0.296 & & 0.967 & 0.285 \\
\hline \multicolumn{6}{|l|}{ Sex } \\
\hline Male & $\begin{array}{c}62.6 \\
(54.5-70.6)\end{array}$ & $\begin{array}{c}66.7 \\
(50.6-82.8)\end{array}$ & $\begin{array}{c}60.0 \\
(29.6-49.4)\end{array}$ & $\begin{array}{c}60.0 \\
(51.2-68.8)\end{array}$ & $\begin{array}{c}67.4 \\
(53.4-81.4)\end{array}$ \\
\hline Female & $\begin{array}{c}37.4 \\
(29.4-45.5)\end{array}$ & $\begin{array}{c}33.3 \\
(17.2-49.4)\end{array}$ & $\begin{array}{c}40.0 \\
(9.6-70.4)\end{array}$ & $\begin{array}{c}40.0 \\
(31.2-48.8)\end{array}$ & $\begin{array}{c}32.6 \\
(18.6-46.6)\end{array}$ \\
\hline p-Value ${ }^{+}$ & & 0.954 & & 0.242 & 0.546 \\
\hline \multicolumn{6}{|l|}{ Carer's level of education } \\
\hline $\begin{array}{l}\text { Not completed high school } \\
\text { (no further training) }\end{array}$ & $\begin{array}{c}17.5 \\
(10.7-24.3)\end{array}$ & & & $\begin{array}{c}16.2 \\
(9.1-23.2)\end{array}$ & $\begin{array}{c}17.1 \\
(4.7-29.6)\end{array}$ \\
\hline $\begin{array}{l}\text { Not completed high school } \\
\text { (further training) }\end{array}$ & $\begin{array}{c}10.0 \\
(4.6-15.4)\end{array}$ & $\begin{array}{c}24.1 \\
(8.6-39.7)\end{array}$ & $\begin{array}{c}30.0 \\
(1.6-58.4)\end{array}$ & $\begin{array}{c}14.3 \\
(7.6-21.0)\end{array}$ & $\begin{array}{c}20.0 \\
(6.7-33.3)\end{array}$ \\
\hline $\begin{array}{l}\text { Completed high school or } \\
\text { further tertiary training } \\
\mathrm{p}^{-V^{\prime}}\end{array}$ & $\begin{array}{c}72.5 \\
(64.5-80.5)\end{array}$ & $\begin{array}{c}75.9 \\
(60.3-91.4) \\
0.017\end{array}$ & $\begin{array}{c}70.0 \\
(41.6-98.4)\end{array}$ & $\begin{array}{c}69.5 \\
(60.7-78.3) \\
0.838\end{array}$ & $\begin{array}{c}62.9 \\
(46.8-78.9) \\
0.397\end{array}$ \\
\hline \multicolumn{6}{|l|}{ Household employment status } \\
\hline Mostly unemployed & $\begin{array}{c}15.1 \\
(9.2-21.1)\end{array}$ & $\begin{array}{c}12.1 \\
(1.0-23.3)\end{array}$ & $\begin{array}{c}20.0 \\
(0-44.8)\end{array}$ & $\begin{array}{c}16.7 \\
(10.0-23.3)\end{array}$ & $\begin{array}{c}25.6 \\
(12.5-38.6)\end{array}$ \\
\hline $\begin{array}{l}\text { Even numbers/excess one } \\
\text { adult employed }\end{array}$ & $\begin{array}{c}35.3 \\
(27.3-43.2)\end{array}$ & $\begin{array}{c}42.5 \\
(25.6-59.3)\end{array}$ & $\begin{array}{c}10.0 \\
(0-28.6)\end{array}$ & $\begin{array}{c}32.5 \\
(24.1-40.9)\end{array}$ & $\begin{array}{c}23.3 \\
(10.6-35.9)\end{array}$ \\
\hline Mostly employed & $\begin{array}{c}49.6 \\
(41.3-58.0)\end{array}$ & $\begin{array}{c}45.5 \\
(28.5-62.4)\end{array}$ & $\begin{array}{c}70.0 \\
(41.6-98.4)\end{array}$ & $\begin{array}{c}50.8 \\
(41.9-59.8)\end{array}$ & $\begin{array}{c}51.2 \\
(36.2-66.1)\end{array}$ \\
\hline p-Value ${ }^{+}$ & & 0.160 & & 0.895 & 0.093 \\
\hline
\end{tabular}

*: 23 subjects answered "not sure"; \#: 21 subjects answered "not sure"; ๆ: 13 subjects answered "not sure"; ${ }^{+}:$these are not adjusted p-values, because of the very small number in cells logistic regression analysis was not feasible.

delivery method, participation rates, definition of asthma) and those related to true difference in prevalence (period and time effect, possible intraregional variations in prevalence). This study utilized a questionnaire validated by the ISAAC [13], modified to suit the local idiom and delivered by local health workers who were trained for the purpose of the study. It is believed that all of these factors contributed to an extremely high participation rate $(97-100 \%)$. In contrast, VeAle et al. [3] used a questionnaire which was not previously validated, not translated to indigenous languages, partially delivered by nonindigenous workers, with participation rates ranging from $51-80 \%$. Given the methodological differences between the two studies, it would not be possible to determine if the different findings between the two studies reflect community or methodological differences or the passage of time.

The present study randomly sampled communities within the Torres Strait region; the children included in the study represented $\sim 39 \%$ of the $0-17-y r-o l d$ population for the entire Torres Strait region [2], and based on an expected prevalence of $15 \%$, the study sample size was sufficient to estimate within $1.7 \%$ of the true population value ( $95 \%$ confidence interval). In addition, while the Torres Strait and the Northern Peninsula Area are geographically remote, there are considerable intercommunity differences in levels of development or Westernization of life style, as well as differences in racial mix, and these could have also accounted for the inconsistency between this study and that of VEALE et al. [3].

The difference in the definition of asthma may also account for some of the disparity in prevalence between the two studies. Veale et al. [3] defined asthma as the presence of symptoms and airway hyperresponsiveness (AHR) [3]. However, the presence of AHR in paediatric asthma is controversial [14, 15] and is generally reported as being of limited value in population studies in all age ranges [16]. While asthmatics must be hyperresponsive on some occasions, AHR is not synonymous with asthma [16-18] and PEARCE et al. [17] argue that clinical asthma, rather than AHR, should be the focus of population surveys, particularly as the sensitivity and specificity of AHR in defining asthma is low. While the direction 
Table 4. - Self-reported prevalence of respiratory symptoms and 95\% confidence intervals by ethnic background, age group, sex, carer's level of education, employment status of the household and community (adjusted p-value for the difference between the groups)

$\begin{array}{ll}\text { Ever had wheezing? } & \text { Wheezing in the } \\ \text { last } 12 \text { months? } & \begin{array}{c}\text { had short wind? } \\ \text { (asthma) }\end{array}\end{array}$

\begin{tabular}{lccc}
\hline Ethnic background & & & \\
Indigenous (at least one parent indigenous) & $19.9(17.8-21.9)$ & $11.5(9.8-13.2)$ & $16.2(14.2-18.1)$ \\
Caucasian parents & $30.3(21.3-39.4)$ & $23.2(14.9-31.6)$ & $12.4(5.8-18.9)$ \\
South Pacific Islander parents and others & $10.4(3.1-17.8)$ & $7.5(1.2-13.8)$ & $10.4(3.0-17.8)$ \\
p-Value & 0.244 & 0.426 & 0.611 \\
Age yrs & & & $16.0(12.9-19.1)$ \\
$0-4$ & $23.0(19.4-26.6)$ & $19.1(15.8-22.5)$ & $14.4(11.3-17.5)$ \\
$5-9$ & $20.0(16.4-26.5)$ & $10.3(7.6-12.9)$ & $15.8(12.3-19.5)$ \\
$10-14$ & $18.3(14.5-22.1)$ & $8.6(5.9-11.4)$ & $18.3(13.0-23.5)$ \\
$15-17$ & $20.1(14.7-25.6)$ & $8.9(5.0-12.8)$ & 0.133 \\
p-Value & 0.501 & 0.003 & $17.7(15.2-20.3)$ \\
Sex & $23.3(20.5-26.1)$ & $15.2(12.9-17.6)$ & $13.8(11.3-16.2)$ \\
Male & $17.6(14.9-20.3)$ & $9.8(7.7-11.9)$ & 0.025 \\
Female & 0.003 & 0.003 & $12.9(9.7-16.1)$ \\
p-Value & & & $18.7(13.4-23.9)$ \\
Carer's level of education & $14.8(11.4-18.2)$ & $6.4(4.0-8.7)$ & $18.1(15.2-20.9)$ \\
Not completed high school (no further training) & $20.8(15.2-26.3)$ & $13.0(8.5-17.6)$ \\
Not completed high school (further training) & $26.2(23.0-29.4)$ & $18.0(15.2-20.9)$ & 0.283 \\
Completed high school or further tertiary training & 0.013 & 0.004 & $12.7(9.6-15.7)$ \\
p-Value & & & $15.0(12.2-17.7)$ \\
Household employment status & $16.4(13.0-19.8)$ & $7.5(5.1-9.9)$ & $19.6(16.2-22.9)$ \\
Mostly unemployed & $17.1(14.1-20.0)$ & $10.7(8.3-13.1)$ & 0.344 \\
Even numbers/excess one adult employed & $28.3(24.5-32.1)$ & $19.2(15.9-22.6)$ \\
Mostly employed & 0.008 & 0.003 & \\
p-Value &
\end{tabular}

Data presented as prevalence ( $95 \%$ confidence interval) unless otherwise stated. ${ }^{*}$ : ethnic background was collapsed into three categories because of the very small numbers in the "others" category; ": adjusted p-values were obtained through logistic regression analysis where age group (in four categories), sex, education, ethnic background, employment and community were included in the model.

of differences that may have occurred by including AHR in the definition cannot be resolved, it is believed that this considerable body of evidence against the use of AHR in prevalence studies suggests that the inclusion of AHR would not have provided support for estimating prevalence of asthma in the present study.

While it might be argued that the prevalence of asthma symptoms is high, there is indirect supportive evidence of the high prevalence of asthma in other indigenous communities. In an indigenous rural community in Western Australia, Bremner et al. [5] described a high prevalence $(24 \%)$ of wheeze in female patients $<18$ yrs of age. WILLIAMs et al. [18] reported that in Western Australia, where indigenous status has been collected as part of the hospital record for several years, the admission rate for asthma was higher for indigenous than nonindigenous children (rate ratios for indigenous versus nonindigenous children ranged 1.4-5.3). While hospitalization data are not good proxy for prevalence and accuracy is questionable, at the very least, the Western Australian data suggest that serious asthma requiring hospitalization is more common among indigenous children. This is consistent with overseas studies which found the prevalence of asthma to be higher in economically disadvantaged groups [19]. However, on the contrary, data from the Northern Territory suggests higher annual hospitalization rates per 1,000 population for nonindigenous children with a principal diagnosis of asthma: 2.6-4.7 for indigenous children and 5.5 for nonindigenous [20]. Remoteness of the indigenous children in this latter study may have lead to bias with an underestimation with respect to hospitalization of indigenous children. Its results are also limited by the retrospective nature of the study and the gross calculation of rates. In addition, the belief that asthma in indigenous children is nonexistent [3] and infectious disease is the dominant illness, may have lead to an underestimation of asthma diagnosis [21].

Knowing the prevalence of diseases is extremely important for the clinical management of patients. However, extending this knowledge to the local setting not only impacts on the clinical care but also on public health management, such that better planning and management of medical care needs can be undertaken [22]. Also, exploration of intercommunity differences may contribute to the understanding of changing prevalence of asthma and possible causative links, in particular the influence of socioeconomic factors. Significant intercommunity differences in prevalence of asthma symptoms even in neighbouring communities were found, some of these being partially explained by variations in sex, age, education and employment status. Mainland communities, Bamaga and Umagico, are only separated by $3 \mathrm{~km}$, the former community being made up of Torres Strait Islander racial groups while the latter is 
predominantly Australian Aboriginal. Their socioeconomic profiles were significantly different, with Umagico having the highest unemployment and incomplete schooling rates, yet the prevalence of asthma symptoms was significantly lower than Bamaga. On the contrary, Warraber Island which had a higher unemployment rate than Saibai Island had a higher prevalence of asthma symptoms. While there are studies reporting the association between asthma and poverty, RonA [23] pointed out that to date there is a lack of consistent evidence that some aspects of poverty cause asthma. However, there is overwhelming evidence that poverty is a contributor to asthma exacerbations and severity. Different research groups also argue that cultural differences [24] (cultural barriers to self-care), communication difficulties [25] (different ethnic groups use different words to describe symptoms) and doctor/patient interactions can also help to explain why asthma affects different minority groups differently. Socioeconomic factors could not, however, explain all of the differences between communities studied; they also have diverse landscape and climate conditions affecting the prevailing air particles [26], and these factors could also have contributed to the findings. This study cannot fully explain the reasons for the differences observed, but further exploration within these communities would be beneficial to many aspects of healthcare and management.

Although the standardized ISAAC questionnaire was used, which is generally accepted as being a good epidemiological tool, ensuring comparable information between centres and countries [11], it is not known how the ISAAC data relate to clinical asthma or to true prevalence in indigenous groups. In addition, there are inherent difficulties with the diagnosis of asthma in children $<3$ yrs of age [16] and the ISAAC questionnaire was not designed for younger children. While it is the intention to carry out a longitudinal assessment of this age range, only $23 \%$ of 0 -3-yr-olds reported ever wheezing and $15 \%$ reported ever having asthma. When data were stratified across demographic factors, there were some variations between the different age groups; however, chance could not be ruled out for age variations of most questions. While this does not exclude "diagnostic drift" across age ranges, that is, bronchiolitis symptoms becoming asthma symptoms, the relatively high rates of symptoms in the past year tends to affirm that the present results have not been influenced by the inclusion of this age range. Indeed, it could be that all studies of children using ISAAC protocols are influenced by "diagnostic drift".

It is concluded that the prevalence of asthma symptoms in these remote indigenous communities is much higher than previously reported, and is comparable to nonindigenous urban centres. Furthermore, significant intercommunity variation exists and exploration of this may contribute to the understanding of paediatric asthma. This paper highlights some of the difficulties in making comparisons and of understanding the extent of the problems and the true prevalence of asthma in indigenous communities. Because of the plight of many indigenous communities/groups, and the potential for misdiagnosis from questionnaire data, these results exemplify the need for further studies designed to measure true prevalence of clinically diagnosed childhood asthma.

\section{Appendix}

Questions for wheezing and asthma (* these questions are part of the core questionnaire wheezing module for 6-7-yr-olds from the ISAAC protocol [8]). Creole words added or modifications made to the questionnaire are in bold.

*Q1- Has your child ever had wheezing or whistling sound in the chest at any time in the past?

$\square$ Yes $\square$ No $\square$ Not sure

If No or Not sure, than go to Q6

*Q2- Has your child had wheezing or whistling sound in the chest in the last 12 months?

$\square$ Yes $\square$ No $\square$ Not sure

If No or Not sure, then go to Q6

*Q3- How many attacks of wheezing sound has your child had in the last 12 months?

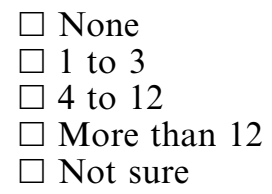

*Q4- In the last 12 months, how often, or how many times, has your child's sleep been disturbed due to wheezing sound?

$\square$ Never wake up with wheezing sound

$\square$ Less than one night per week

$\square$ One or more nights per week

Not sure

*Q5- In the last 12 months, has wheezing sound ever been big enough to limit your child's speech to only 1 or 2 words at a time between breaths?

$\square$ Yes $\square$ No $\square$ Not sure

*Q6- Has your child ever had short wind? (asthma)

$\square$ Yes $\square$ No $\square$ Not sure

*Q7- In the last 12 months, has your child's chest sounded wheezy during or after exercise?

$\square$ Yes $\square$ No $\square$ Not sure

Q8- When your child is playing does she/he become more short of breath compared to other children?

$$
\square \text { Yes } \square \text { No } \square \text { Not sure }
$$

Q9- Does your child tire more easily than other children do?

$\square$ Yes $\square$ No $\square$ Not sure

Q10- In the last 12 months, has your child taken any medication (mersin, pills or puffers) for wheezing 


\section{sound or short wind? $\square$ Yes $\square$ No $\square$ Not sure (SHOW MEDICINE CARD)}

*Q11- In the last 12 months, has your child had a dry cough at night, when she/he hasn't got a cold or chest infection?

$$
\text { Yes } \square \text { No } \square \text { Not sure }
$$

10. Coultas DB, Gong H Jr, Grad R, et al. Respiratory diseases in minorities of the United States. Am J Respir Crit Care Med 1994; 149: S93-S131.

11. Asher MI, Weiland SK. The International Study of Asthma and Allergies in Childhood (ISAAC). ISAAC Steering Committee. Clin Exp Allergy 1998; 28: 52 66.

12. Robertson CF, Dalton MF, Peat JK, et al. Asthma and other atopic diseases in Australian children. Med J Aust 1998; 168: 434-438.

13. Jenkins MA, Clarke JR, Carlin JB, et al. Validation of questionnaire and bronchial hyperresponsiveness against respiratory physician assessment in the diagnosis of asthma. Int J Epidemiol 1996; 25: 609-616.

14. Pearce N, Beasley R, Pekkanen J. Role of bronchial responsiveness testing in asthma prevalence surveys. Thorax 2000; 55: 352-354.

15. Wilson N, Silverman M. Bronchial responsiveness and its measurements. In: Silverman M, editor. Childhood asthma and other wheezing disorders. London, Chapman \& Hall, 1995; pp. 142-174.

16. Silverman $\mathrm{M}$, Wilson N. Wheezing phenotypes in childhood. Thorax 1997; 52: 936-937.

17. Pearce N, Beasley R, Burgess C, Crane J. Asthma epidemiology: principles and methods. New York, Oxford University Press, 1998.

18. Williams P, Gracey M, Smith P. Hospitalisation of Aboriginal and non-Aboriginal patients for respiratory tract diseases in Western Australia, 1988-1993. Int J Epidemiol 1997; 26: 797 -805.

19. Mielck A, Reitmeir P, Wjst M. Severity of childhood asthma by socio-economic status. Int $J$ Epidemiol 1996; 25: $388-393$.

20. Whybourne AM, Lesnikowski CL, Ruben AR, Walker AC. Low Rates of Hospitalisation for Asthma among Aboriginal Children Compared to Non-Aboriginal Children of the Top End of the Northern Territory. J Paediatr Child Health 1999; 35 : $438-441$.

21. Clark CE, Coote JM, Silver DA, Halpin DM. Asthma after childhood pneumonia: six year follow up study. BMJ 2000; 320: 1514 - 1516 .

22. Hennekens C, Buring J. Epidemiology in Medicine. First Edn. Boston, Little, Brown and Company, 1987.

23. Rona R. Asthma and poverty. Thorax 2000; 55: 239 244.

24. Partridge M. In what way may race, ethnicity or culture influence asthma outcomes? Thorax 2000; 55: $175-176$.

25. Hardie G, Jason S, Gold W, Carrieri-Kohlman V, Boushey H. Ethnic differences: word descriptors used by African-American and white asthma patients during induced bronchoconstriction. Chest 2000; 117: $935-943$.

26. Rutherford S, Clark E, McTainsh G, Simpson R, Mitchell C. Characteristics of rural dust events shown to impact on asthma severity in Brisbane, Australia. Int J Biometeorol 1999; 42: 217-225. 